of closer links between scientific workers in the Dominions and in the older seats of learning and centres of research, but also that the people of all nations will benefit. It is also hoped that it will be anjmportant contribution to Imperial unity.

\section{Scientific Approach to Foreign Affairs}

IN the latert 9 final "Looking Forward Pamphlet" (N 9 ) d the Royal Institute of International Affairs, ofde the title "Foreign Affairs and the Pupie" Wr. John Price deals with the connexion befuron foreign affairs and the daily interests of the indifidual citizen. Explaining first the subject. matter of foreign affairs, he shows how the human element as well as questions of trade and security enter into it. Considerations of human conduct and morality complicate international affairs, and the greatest difficulties arise not from the problems themselves but from the policies of nations and governments determined to pursue their selfish ends by every possible means. The study of international affairs is not an exact science, nor concerned with the relations between nations in the abstract: it is a study of human affairs. That must be remembered in appraising the machinery for the conduct of foreign affairs, whether at the national or the international level. This machinery is well reviewed by Mr. Price in his next section, which gives a very clear picture of the limitation and purposes of world organisation. The new international organisations are being established in one sphere after another where the need for them is clearly felt, and machinery for collaboration at different levels and in all spheres must be provided if the tasks of maintaining security and promoting peace are to be accomplished.

The purpose of security, however, is to provide the conditions in which civilization and culture can prosper, and Mr. Price then reviews both the methods and policies by which foreign affairs are conducted, and emphasizes finally the need for pursuing actively policies based upon international co-operation and world organisation. The fundamental difficulty the nations have to face is the reconciliation of national self-interest with the common good of the world as a whole. That is why public interest in foreign affairs is so important. We need experts, but we need also citizens who are able to see clearly, to judge shrewdly and to realize whether they are being given the essential facts. We have to ensure that there are enough experts in the foreign service, and that they possess the requisite qualifications; but it is equally important that the ordinary citizen should have access to accurate, abundant and up-todate information to enable him to understand more about the problems and difficulties, the needs and aspirations, the history and traditions of other countrifs gnd nations.

\section{East Afrlcan Industrial Research Board}

The thire aphual report of the East African Industrial Ressarch Board (P.O. Box 1587, Nairobi. 1s. 6d. . cepers the year ended December 31, 1945, and ind to in addition to the chairman's report, tho oN the Tanganyika Industrial Committee and the Uganda Industrial Committee. Dr. A. J. V. Underwood continued to serve as overseas consultant, and the main preoccupation of the Board has been planning for the future of industrial research in East Africa. So far the governments concerned have not all accepted the proposals formulated by the chairman for an East African Department of Industrial Research and Development. The Board's research organisation continued on its war-time basis, but staff difficulties are expected to restrict its services in 1946. The technical publications of the Board appear to be meeting a public need, and a small technical library has been built up. While much of the time of the Chemical Laboratory has been occupied by analytical work, important work has been done on the development of phosphatic fertilizers, and a new product, 'Silicophosphate', is now undergoing extensive field trials. Methods of mining salt from the salt lakes of Uganda have been under examination, and the improved quality of domestic pottery is largely due to the work of the Ceramics Branch. Attention was also given to the improvement of oil milling and soap manufacture, and draft specifications for soaps were prepared by the Panel on Oils and Fats and later adopted by the Government of Kenya.

The report of the Tanganyika Industrial Committee reviews the activities of the Hones factory, including slate pencil manufacture, which was closed on October 15, and of the Totaquina factory where a study of the quality and efficiency of extraction has established the relation between the total alkaloidal content of the bark and the quality and efficiency of extraction of the total alkaloids. The. Uganda Industrial Committee is being disbanded this year, and the pottery, which did not enjoy a prosperous year, will then come under the direction of the Geological Survey.

\section{Proceedings of the hademy of Sciences, Vienna}

VOLUMES .148 151 inclusive, covering the years 1939-42, of futtion II $a$ of the Proceedings of the Academy Sciences, Vienna, in which are published article on astronomy, mathematics, meteorology, plysics and technology, have recently been received. The number of articles contained in each volume is substantially the same; but this is considerably less than for volume 147, for 1938. A reduction in the page size of the pamphlet was made in 1940, and, in addition, in the following year, paper of an inferior and darker quality was introduced. The majority of the articles are theoretical. Of the experimental articles, those on the light properties of stars by K. Graff, and the "Communications from the Institute of Radium Research", of which several appear in each volume, are worthy of special mention. As is to be expected, the latter deal mainly with the properties of uranium and thorium, fission products and the effects of neutron bombardment. The purely mathematical papers include one on Laguerre's polynomials by A. Erdélyi, on the Euler-Maclaurin series and Bernouilli's numbers by A. Klingst, and on differential geometry by K. Strubecker.

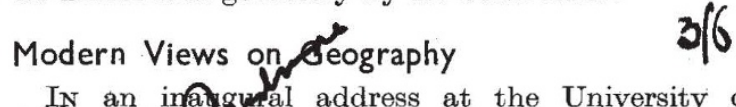

IN an in@gyal address at the University of Liverpool efictled "ryne Theory and Practice of Geographr' Unprersity Press of Liverpool ; London : Hoddes and Stputiton, Ltd. 1s. net), Prof. H. C. Darby stressed the changes in ways of thought of thepte eighteenth and early nineteenth centuries wheh had made place for the modern geographical outlook. He cited specially the widening of the scope of history, the rise of the social sciences and particularly the writings of F. Le Play, and the voyage of the Beagle with Darwin's stress on the importance of environment. Thus there was prepared the way for such geographical writers as A. von 
Humboldt and K. Ritier. In spite of the great progress made in geographical thought in recent decades, there is a noticeable lack, at least in English, of objective geographical studies of most parts of the world. British geography has progressed more on the study of topics than that of regions. Prof. Darby spoke of the importance of more regional study, especially with a historical bias, since the character of a region is based not merely on physical and economic facts, but also on the legacies of succesfive generations of its inhabitants.

\section{Documentation in.Switzerland}

A sEcond pompletely revised and augmented edition af " threr durch die Schweizerische Dokumepat op', by Theodore van Schelven (Amsterdam: Kopplos bublishing Co., Keizersgracht 133. 1 dollar), has now been published by the Swiss Association for Documentation. The pamphlet has proved of considerable value to Swiss research workers during the war years, since it quotes collections containing literature lacking in the large Swiss scientific libraries and which could not be included in the general catalogue of the Swiss National Library. The new edition lists 227 documentation centres arranged by subject according to the Universal Decimal Classification, together with alphabetical name, subject and place indexes, and a list of users of the Universal Decimal Classification. The introduction includes brief notes on the Swiss Association for Documentation, the Swiss Association of Librarians, the general catalogue and information service of the Swiss National Library, Berne, on documentation terminology, the standardization of documentary aids and a bibliography of publicutions of Swiss authors on documentation, biblingraphy and the decimal classification.

\section{Silicon Carbide Non-ohmic Resistors}

During the past de ade, resistors having silicon carbide as tos ing chant and characterized by a striking 4 part from Ohm's law-the current passed ing propertional to the fourth or fifth power of th itplied viljage-have become available commfoldy and are now widely used in many fields of lectrical engineering. Their development was first stimulated by the requirements of surge diverters (lightning arresters) for overhead power transmission lines, but success in this application had led to their use for the protection, /at much lower voltages, of the highly inductive coils found in electrical machinछry, contactors, clutches, brakes, relays, etc. An important advantage arising from the limitation of the peik voltage developed when such coils are disconnected from the supply is the reduction of the sparking at opening contacts, and of the radio interference to which such sparking gives rise. This method of spark quenching has received particular attention in connexion with telephone relays, where the preservation of contacts is of great importance. Silicon carbide resistors have also found application for the protection of radio transmitting and receiving circuits and of electrical instruments, and for scale modification in the latter; in metadyne systems, where they permit practically any desired main motor characteristic to be obtained; and in non-linear bridge circuits. The characteristics and limitations of these resistors, and the principles governing their application, are discussed in a recent paper by Messrs. F. Asliworth, W. Needham and R. W. Sillars (J. Inst. Elect. Eng., 93, Part 1, No. 69; Sept. 1946), with which is associated an extensive discussion.

\section{Research on Multiple Sclerosis}

THE Association for Advancement of Research on Multiple Sclerosis, the address of which is New Yark Academy of Medicine Building, Fifth Avenue and 103rd Street/New York 29, N.Y., has been formed by a group of multiple sclerosis patients, with their many frionds and relatives, in co-operation with some of the leading neurologists of North America. Its gims are : (1) co-ordination of research efforts on myltiple sclerosis; (2) collection of statistics on its prevalence and geographical distribution; (3) to act as a clearing house for information on this disease; (4) education of the public on the problem of multiple sclerosis; (5) collection of funds to stimulate and support research on multiple sclerosis and allied diseases. For the present, the Association proposes to conduct a membership drive for the enrolment of multiple sclerosis patients as well as the public, in an endeavour to obtain more definite statistical data on the prevalence of the disease. Dr. Tracy Jackson Putnam, director of Services of Neurology and Neurological Surgery, Neurological Institute of New York, is the honorary chairman of the Association.

\section{Institution of fivil Engineers \\ 6.6}

SIR WILTIAM fulconow, in his presidential address to the Instify on of Civil Engineers on November 5, reviefer of accomplishments of the Institution, mor fasticalarly during the past fifteen of the 128 ont that it has been in existence. Not every eppin will agree with Sir William's opinion that too much reliance should not be placed on theoretical knowledge. Engineering is an applied science, and therefore the provision of facilities for practical training, as distinct from practical experience, cannot receive too much attention from the Institution; but it is impossible for the engineer to have too much knowledge of the fundamentals or theoretical basis of his science. The civil engineer's record during the War when, as Sir William points out, 'Mulberry' and 'Pluto' were designed, would have been even more spectacular if fundamental knowledge, essential in dealing with new and complex problems, had been more widespread.

Another matter of considerable moment, dealt with by Sir William in his address, was the difficulty met with to-day in presenting the views of the profession as a whole on matters of public interest, due to the large number of engineering institutions which exist. While the Institution's present policy of setting up sectional divisions specializing in the various branches of professional work may make unnecessary the ereation of more institutions, it is unlikely to do much to encourage the existing smaller institutions to amalgamate. The value of amalgamation which would enable engineers, who should form a most influential section of the community, to speak with one voice, is recognized by all but a very small minority. That small minority, however, inevitably includes the most influential and hard-working members of the smaller institutions, who are naturally governed by a sense of loyalty to their own organisations. It will need a measure of self-sacrifice and a sense of wider loyalty to the profession as a whole to right the position.
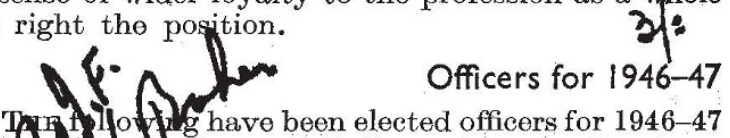

'TIS f I o flg have been elected officers for 1946-47 of thIntution of Civil Engineers: President, Sir Willam Halcrow; Vice-Presidents, Sir Frederick 